\title{
Pengaruh Menstruasi Terhadap Profil Hematologi Pada Siswi SMPN 22 Bandar Lampung
}

\author{
Maria Tuntun ${ }^{1}$, Pudji Rahayu ${ }^{2}$ \\ ${ }^{1}$ Jurusan Analis Kesehatan Politeknik Kesehatan Tanjungkarang \\ ${ }^{2}$ Jurusan Farmasi Politeknik Kesehatan Tanjungkarang
}

\begin{abstract}
Abstrak
Siklus menstruasi dapat mempengaruhi kesehatan remaja putri, seperti ketidakteraturan menstruasi, menoragia, dismenorea dan lain-lain. Tujuan penelitian ini mengetahui pengaruh menstruasi terhadap profil hematologi pada siswi SMPN 22 Bandar Lampung. Penelitian dilakukan di SMPN 22 Kota Bandar Lampung, dan pemeriksaan profil hematologi dilakukan di laboratorium rumah sakit Dr.H.Abdoel Muluk Bandar Lampung, pada bulan Oktober - November 2016. Pemeriksaan profil hematologi meliputi jumlah lekosit, jumlah trombosit, jumlah eritrosit, kadar hemoglobin, kadar hematokrit Populasinya adalah seluruh siswi kelas VIII SMPN 22 Kota Bandar Lampung, dan sampelnya sebanyak 68 siswi, yang bersedia di ambil darah venanya. Hasil penelitian menunjukkan korelasi yang sangat lemah dan tidak signifikan $(p>0,05)$ antara lama menstruasi dengan profil hematologi, yaitu makin lama menstruasi maka makin sedikit jumlah lekosit, dan makin rendah kadar hemoglobin, tetapi makin banyak jumlah trombosit, jumlah eritrosit, dan kadar hematokrit. Sedangkan hubungan siklus menstruasi dengan jumlah lekosit, jumlah trombosit, dan jumlah eritrosit menunjukkan korelasi yang sangat lemah. Tetapi hubungan siklus menstruasi dengan kadar hemoglobin dan kadar hematokrit menunjukkan korelasi yang kuat walaupun tidak signifikan $(\mathrm{p}>0,05)$. Korelasi yang signifikan terjadi antara siklus menstruasi dengan jumlah lekosit dan jumlah eritrosit, karena nilai $\mathrm{p}<0,05$.
\end{abstract}

Kata Kunci : menstruasi, siswi SMP, profil hematologi

\section{The Effect of Menstruation on Hematology Profiles in Students SMPN 22 Bandar Lampung}

\begin{abstract}
Menstrual cycles can affect the health of adolescent girls, such as menstrual irregularities, menorrhagia, dysmenorrhoea and others. The purpose of this study was to determine the effect of menstruation on the hematological profile of SMPN 22 Bandar Lampung students. The study was conducted at SMPN 22 Bandar Lampung City, and examination of the hematological profile was carried out in the Dr.H.Abdoel Muluk hospital laboratory in Bandar Lampung, in October - November 2016. The hematological profile examination included the number of leukocytes, platelet counts, number of erythrocytes, hemoglobin levels, hematocrit levels The population is all eighth grade students of SMPN 22 Bandar Lampung City, and the sample is 68 female students, who are willing to take venous blood. The results showed a very weak and insignificant correlation $(p>0.05)$ between the duration of menstruation and the haematological profile, ie the longer the menstruation the less the number of leukocytes, and the lower the hemoglobin level, but the more platelet counts, the number of erythrocytes, and hematocrit levels. While the relationship of the menstrual cycle with the number of leukocytes, platelet counts, and the number of erythrocytes shows a very weak correlation. But the relationship of the menstrual cycle with hemoglobin levels and hematocrit levels showed a strong correlation although not significant ( $p>0.05$ ). Significant correlation occurred between the menstrual cycle with the number of leukocytes and the number of erythrocytes, because the $\mathrm{p}$ value $<0.05$.
\end{abstract}

Keywords: menstruation, junior high school students, hematology profile

Korespondensi: Maria Tuntun Siregar, Jurusan Analis Kesehatan Politeknik Kesehatan Tanjungkarang, Jalan Soekarno-Hatta No. 1 Bandar Lampung, mobile 085279583168,e-mail maria_tuntun@yahoo.com 


\section{Pendahuluan}

Siswi sekolah menengah pertama merupakan kelompok remaja putri yang mengalami masa transisi menuju dewasa. Remaja adalah tahap umur 8-14 tahun dengan ciri-ciri pertumbuhan yang cepat dan timbulnya ciri-ciri kelompok sekunder, salah satunya adalah menstruasi. Remaja dalam masa pertumbuhannya membutuhkan energi, protein dan zat gizi lainnya yang lebih banyak dibanding dengan kelompok umur lainnya. Pematangan seksual pada remaja menyebabkan kebutuhan zat besi meningkat. Kebutuhan zat besi remaja perempuan lebih tinggi dibandingkan remaja laki-laki, karena dibutuhkan untuk mengganti zat besi yang hilang pada saat menstruasi.

Menstruasi didefinisikan sebagai perdarahan secara periodik dan siklik dari uterus, disertai pelepasan (deskuamasi) endometrium. Menstruasi yang berulang setiap bulan tersebut akan membentuk siklus menstruasi (Prawirohardjo, 2005).

Adanya siklus menstruasi setiap bulan yang dialami remaja putri merupakan suatu keadaan yang mempengaruhi kesehatan. Jika seorang wanita mengalami siklus menstruasi yang pendek dan mengalami menstruasi yang lama ( $>8$ hari), maka akan kehilangan zat besi di atas rata-rata (Proverawati, 2011).

Menstruasi merupakan tahap akhir pubertas, umumnya menarke terjadi dalam dua tahun sejak terjadi perkembangan payudara dengan rerata pada usia 12,8 tahun dengan rentang usia 10-16 tahun (Pulungan, 2010) Berbagai masalah yang timbul pada menstruasi merupakan masalah ginekologi yang sering dikeluhkan pada remaja, seperti ketidakteraturan menstruasi, menoragia, dismenorea, dan gejala lain yang berhubungan. Di antara keluhan tersebut, dismenorea yang paling umum dilaporkan, terjadi pada $60 \%-90 \%$ remaja, dan merupakan penyebab paling sering alasan ketidakhadiran di sekolah dan pengurangan aktivitas sehari-hari (Singh A, 2008). Hasil penelitian Wahyuningsih (2012) didapatkan 28,6\% mahasiswi Kebidanan mengalami ketidakteraturan siklus menstruasi.

Panjang siklus menstruasi yang normal atau dianggap sebagai siklus menstruasi klasik adalah 28 hari, tetapi variasinya cukup luas biasanya berlangsung selama kurang lebih 7 hari.Lama perdarahan sekitar 3-5 hari dengan jumlah darah yang hilang sekitar 30-40 cc (Bobak, 2004). Adanya perubahan dan gangguan dalam siklus menstruasi merupakan indikator penting yang menunjukkan adanya gangguan fungsi sistem reproduksi yang dapat dihubungkan dengan peningkatan risiko berbagai macam penyakit, seperti kanker rahim dan payudara, infertilitas, dan fraktur tulang (Handayani, 2008). Selain itu, gangguangangguan dalam siklus menstruasi termasuk ketidakteraturan siklus menstruasi dapat menimbulkan masalah sosial, yaitu kecemasan yang apabila berkepanjangan dapat mempengaruhi kualitas hidup seorang wanita (Permaesih, 2002).

Penelitian Cakir M et al (2007) menjelaskan temuan gangguan siklus menstruasi dengan prevalensi terbesar adalah dismenorea $(89,5 \%)$, diikuti ketidakteraturan siklus menstruasi $(31,2 \%)$, dan perpanjangan durasi menstruasi (5,3\%). Gangguan menstruasi ini $75 \%$ dialami oleh banyak wanita pada tahap remaja akhir, yaitu kisaran usia 15-18 tahun (Sarwono, 2006)

Siklus menstruasi dan lamanya menstruasi yang tidak teratur dapat menyebabkan perubahan komposisi darah, yaitu jumlah sel-sel darah menjadi berkurang, baik itu sel darah merah (eritrosit), sel darah putih (lekosit) maupun sel trombosit. Hal ini dapat menyebabkan keadaan anemia.

Data Survei Kesehatan Rumah Tangga (SKRT) tahun 2004 menunjukan bahwa prevalensi anemia defisiensi besi pada remaja putri usia 10-18 tahun sebesar 57,1\% dan usia 19-45 tahun sebesar 39,5\%. Data WHO (2008) menyebutkan bahwa prevalensi anemia pada wanita di kawasan Asia Tenggara (usia 15-49 tahun) adalah 45,7\%, sedangkan di Indonesia memiliki prevalensi anemia pada wanita usia reproduktif mencapai $33,1 \%$.

Tingginya prevalensi anemia pada remaja putri ini dapat dilihat dari hasil penelitian Sandra (2005) yaitu sebanyak 31,89\% siswi SLTP di Tangerang mengalami anemia. Pada penelitian Dilla Nursari (2010) didapatkan prevalensi anemia siswi SMPN 18 Kota bogor mencapai 59,3\%. Hal ini diperkuat oleh data hasil Riset Kesehatan Dasar (Riskesdas) tahun 2013, yang menunjukkan prevalensi anemia gizi besi secara nasional pada remaja putri usia 13-18 tahun sebesar 22,7\%. Penelitian Wahyu (2015) yaitu sebanyak 59,5\% siswi SMAN 8 di Pekanbaru mengalami anemia, hasil penelitian Dinas Kesehatan Kota Yogyakarta dan Fakultas Kedokteran UGM (2012) yang menunjukkan bahwa $34 \%$ dari 280 remaja putri/siswi SMA mengalami anemia yang disebabkan karena kesalahpahaman mengenai diet di kalangan remaja (Pemerintah Kota Jogja, 2013). 
Penelitian Farida (2006) menunjukkan prevalensi anemia remaja putri di Kecamatan Gebog Kabupaten Kudus sebesar 36,8\%. Sebagian besar remaja putri mempunyai orang tua dengan tingkat pendapatan dan pendidikan yang rendah. Hasil uji korelasi menunjukkan ada hubungan pendidikan orang tua, pendapatan orang tua, pengetahuan dan sikap remaja putri tentang anemia dengan tingkat konsumsi gizi.

Berdasarkan hasil observasi peneliti pada siswi siswi kelas VIII SMPN 22 Bandar Lampung sebagian besar $(70 \%)$ berasal dari program bina lingkungan. Program bina lingkungan (billing) merupakan program khusus bagi siswa siswi Bandar Lampung yang berasal dari keluarga yang tidak mampu, serta berada pada lingkungan sekolah tersebut. Siswi SMPN 22 Bandar Lampung yang berasal dari keluarga tidak mampu merupakan salah satu kelompok yang beresiko kekurangan asupan gizi. Kekurangan gizi dapat mempengaruhi produksi estrogen dan menyebabkan gangguan keteraturan siklus menstruasi dan lamanya menstruasi. Tujuan penelitian ini mengetahui pengaruh menstruasi terhadap profil hematologi pada siswi SMPN 22 Bandar Lampung.

\section{Metode}

Jenis penelitian ini adalah deskripsi, dengan desain cross sectional. Penelitian dilaksanakan di SMPN 22 Bandar Lampung, pada bulan Oktober-November 2016. Jumlah populasi sebanyak 209 siswi kelas VIII, dan yang memenuhi kriteria inklusi sebanyak 85 siswi, tetapi siswi yang bersedia diambil darah vena dan sekaligus sebagai responden sebanyak 68 siswi. Darah vena dari masing-masing responden diperiksa profil hematologi nya di laboratorium klinik rumah sakit Dr.H.Abdoel Muluk Bandar Lampung. Pemeriksaan profil hematologi meliputi jumlah lekosit, jumlah eritrosit, jumlah trombosit, kadar hemoglobin, dan kadar hematokrit. Responden yang bersedia diambil darahnya, mengisi kuisoner tentang menstruasi. Analisis data hasil penelitian ini dilakukan dimulai dari analisis univariat, analisis bivariat dan analisis multivariat, dengan program SPSS versi 17,0.

\section{Hasil}

\section{Analisis Univariat}

Responden dalam penelitian ini adalah siswi kelas VIII. Pada tabel 1 dapat dilihat bahwa umur responden rata-rata 13 tahun, umur termuda 12 tahun dan umur tertua 14 tahun. Rata-rata umur responden pertama kali menstruasi adalah 11,68 tahun, dan umur responden pertama kali menstruasi termuda 10 tahun dan tertua 13 tahun. Lama menstruasi responden rata-rata 6,6 hari, dengan waktu terpendek 2 hari dan terpanjang 13 hari. Siklus menstruasi responden rata-rata 26,25 hari, dengan waktu terpendek 16 hari dan waktu terpanjang 48 hari.

Tabel 1. Distribusi frekuensi umur responden, umur pertama menstruasi, lama menstruasi dan siklus menstruasi

\begin{tabular}{cccccccc}
\hline No & \multicolumn{1}{c}{ Variabel } & N & Mean & Median & Minimun & Maksimum & SD \\
\hline 1 & Umur responden & 68 & 13 & 13,0 & 12 & 14 & 0,531 \\
\hline 2 & Umur pertama menstruasi & 68 & 11,68 & 12 & 10 & 13 & 0,937 \\
\hline 3 & Lama menstruasi & 68 & 6,60 & 7,00 & 2 & 13 & 1.805 \\
\hline 4 & Siklus menstruasi & 68 & 26,25 & 27,00 & 16 & 48 & 4,382 \\
\hline
\end{tabular}

Pada tabel 2 dapat dilihat distribusi frekuensi responden berdasarkan umur pertama kali menstruasi, sakit saat menstruasi, lama menstruasi dan siklus menstruasi

Tabel 2. Distribusi frekuensi berdasarkan umur pertama menstruasi, sakit, lama dan siklus menstruasi

\begin{tabular}{lcc}
\hline \multicolumn{1}{c}{ Variabel } & Frekuensi & Persen $(\boldsymbol{\%})$ \\
\hline Umur pertama menstruasi (tahun) & & \\
\hline 10 & 8 & 11.8 \\
\hline 11 & 20 & 29.4 \\
\hline 12 & 26 & 38.2 \\
\hline 13 & 14 & 20.6 \\
\hline Total & 68 & 100,0 \\
\hline
\end{tabular}




\begin{tabular}{lcc}
\hline Sakit saat menstruasi & 19 & \\
\hline Tidak sakit & 24 & 27.9 \\
\hline Sakit Ringan & 20 & 35.3 \\
\hline Sakit Sedang & 5 & 29.4 \\
\hline Sakit Berat & 68 & 7.4 \\
\hline Total & 1 & 100.0 \\
\hline Lama Menstruasi & 60 & 1.5 \\
\hline Mens < 3 hari (pendek) & 7 & 88.2 \\
\hline Mens 3 - 8 hari (normal) & 68 & 10.3 \\
\hline Mens > 8 hari (panjang) & & 100.0 \\
\hline Total & 22 & \\
\hline Siklus Menstruasi & 44 & 32.4 \\
\hline$<25$ hari (pendek) & 2 & 64.7 \\
\hline $25-32$ hari (normal) & 68 & 2.9 \\
\hline$>32$ hari (panjang) & & 100.0 \\
\hline Total & & \\
\hline
\end{tabular}

Hasil pemeriksaan profil hematologi responden yang terdiri dari pemeriksaan jumlah lekosit, jumlah trombosit, jumlah eritrosit, kadar hemoglobin, kadar hematokrit dapat dilihat pada tabel 3 di bawah ini.

Tabel 3. Distribusi frekuensi hasil pemeriksaan profil hematologi

\begin{tabular}{clccccc}
\hline No & Profil Hematologi & N & Mean & Minimum & Maksimum & SD \\
\hline 1 & Jumlah lekosit & 68 & 8.75 & 5,5 & 13,7 & 1.8499 \\
\hline 2 & Jumlah trombosit & 68 & 352.47 & 192 & 520 & 75.682 \\
\hline 3 & Jumlah eritrosit & 68 & 4.933 & 4,1 & 6,4 & 0.3977 \\
\hline 4 & Kadar hemoglobin & 68 & 13.37 & 9,5 & 15,2 & 1.1533 \\
\hline 5 & Kadar hematokrit & 68 & 38.968 & 29.4 & 43.7 & 2.7707 \\
\hline
\end{tabular}

Berdasarkan tabel 4, didapatkan sebagian besar hasil pemeriksaan profil hematologi dalam batas normal $(61,7$ - 89,7\%), bahkan jumlah lekosit dan jumlah trombosit tidak ada yang rendah (0\%), sedangkan kadar hemoglobin dan kadar hematokrit tidak ada yang tinggi $(0 \%)$. Ada 9 responden $(13,3 \%)$ yang mengalami anemia yaitu mempunyai kadar hemoglobin kurang dari normal. Adanya responden yang mengalami anemia ini juga dikuatkan dengan hasil pemeriksaan jumlah eritrosit rendah terdapat pada 3 responden $(4,4 \%)$ dan hasil pemeriksaan kadar hematokrit rendah terdapat pada 13 responden $(19,1 \%)$.

Tabel 4. Hasil pemeriksaan profil hematologi responden

\begin{tabular}{clccccccccc}
\hline \multirow{2}{*}{ No } & Profil & \multicolumn{2}{c}{ Rendah } & \multicolumn{2}{c}{ Normal } & \multicolumn{2}{c}{ Tinggi } & \multicolumn{2}{c}{ Total } \\
\cline { 3 - 11 } & Hematologi & Jumlah & \% & Jumlah & \% & Jumlah & \% & Jumlah & \% \\
\hline 1 & Jumlah Lekosit & 0 & 0 & 57 & 83,8 & 11 & 16,2 & 68 & 100 \\
\hline 2 & Jumlah trombosit & 0 & 0 & 61 & 89,7 & 7 & 10,3 & 68 & 100 \\
\hline 3 & Jumlah eritrosit & 3 & 4,4 & 60 & 88,2 & 5 & 7,4 & 68 & 100 \\
\hline 4 & Kadar hemoglobin & 9 & 13,3 & 59 & 86,7 & 0 & 0 & 68 & 100 \\
\hline 5 & Kadar hematokrit & 13 & 19,1 & 55 & 80,9 & 0 & 0 & 68 & 100 \\
\hline
\end{tabular}

\section{Analisis Bivariat}

Hasil analisis bivariat dapat dilihat pada tabel 5, yaitu variabel yang berkorelasi secara signifikan adalah variabel siklus menstruasi dengan jumlah lekosit ( $p$ value 0,047 ), dan variabel siklus menstruasi dengan jumlah eritrosit ( $p$ value 0,033 ), karena didapatkan $p$ 
value $<0,05$. Sedangkan variabel lama menstruasi tidak ada yang berkorelasi dengan jumlah lekosit ( $\mathrm{p}$ value 0,867), jumlah trombosit ( $\mathrm{p}$ value 0,430$)$, jumlah eritrosit $(\mathrm{p}$ value 0,198 ), kadar hemoglobin ( $\mathrm{p}$ value 0,768 ) dan kadar hematokrit ( $p$ value 0,674 ), karena $p$ value $>0,05$.

Tabel 5. Hasil analisis bivariat dengan uji korelasi antar variabel

\begin{tabular}{|c|c|c|c|}
\hline & & Lama Menstruasi & Siklus Menstruasi \\
\hline \multirow[t]{3}{*}{ Jumlah lekosit $^{\text {a }}$} & $\mathrm{r}$ & $-0,021$ & $-0,102$ \\
\hline & $p$ & 0,867 & 0,047 \\
\hline & $\mathrm{n}$ & 68 & 68 \\
\hline \multirow[t]{3}{*}{ Jumlah trombosit $^{\text {a }}$} & $\mathrm{r}$ & 0,097 & $-0,014$ \\
\hline & $p$ & 0,430 & 0,913 \\
\hline & $\mathrm{n}$ & 68 & 68 \\
\hline \multirow[t]{3}{*}{ Jumlah eritrosit $^{\text {a }}$} & $\mathrm{r}$ & 0,158 & 0,259 \\
\hline & $p$ & 0,198 & 0,033 \\
\hline & $\mathrm{n}$ & 68 & 68 \\
\hline \multirow[t]{3}{*}{ Kadar Hb } & $\mathrm{r}$ & $-0,036$ & 0,67 \\
\hline & $p$ & 0,768 & 0,588 \\
\hline & $\mathrm{n}$ & 68 & 68 \\
\hline \multirow[t]{3}{*}{ Kadar hematokrit } & $\mathrm{r}$ & 0,052 & 0,86 \\
\hline & $p$ & 0,674 & 0,485 \\
\hline & $\mathrm{n}$ & 68 & 68 \\
\hline
\end{tabular}

Keterangan:

$\mathrm{r}=$ koefesien korelasi; $\mathrm{p}=$ nilai $\mathrm{p} ; \mathrm{n}=$ jumlah sampel

a. Hubungan lama menstruasi dengan jumlah lekosit, trombosit, eritrosit, hemoglobin, dan hematokrit.

Secara umum hubungan lama menstruasi dengan jumlah lekosit $(\mathrm{r}=-0,021)$, jumlah trombosit $(\mathrm{r}=0,097)$, jumlah eritrosit $(\mathrm{r}=$ 0,158), kadar hemoglobin ( $\mathrm{r}=-0,036)$, kadar hematokrit $(\mathrm{r}=0,052)$ menunjukkan korelasi yang sangat lemah karena nilai $r<0,2$ dan tidak signifikan karena nilai $\mathrm{p}>0,05 \quad$ (tabel 5). Adanya tanda negatif menunjukkan makin lama menstruasi maka makin sedikit jumlah lekosit ( $\mathrm{r}$ $=-0,021)$, dan makin rendah kadar hemoglobin $(\mathrm{r}=-0,036)$.

Arah korelasi antara lama menstruasi dengan jumlah trombosit $(\mathrm{r}=0,097)$, jumlah eritrosit $(r=0,158)$, dan kadar hematokrit $(r=$ $0,052)$ menunjukkan arah positif, artinya makin lama menstruasi maka makin banyak jumlah trombosit, makin banyak jumlah eritrosit, dan makin banyak kadar hematokrit yang hilang saat menstruasi.

b. Hubungan siklus menstruasi dengan1. jumlah lekosit, trombosit, eritrosit, hemoglobin, dan hematokrit.

Secara umum hubungan siklus menstruasi dengan jumlah lekosit $(r=-0,102)$, jumlah trombosit $(r=-0,014)$, jumlah eritrosit $(r$ $=0,259)$, menunjukkan korelasi yang sangat lemah karena nilai $\mathrm{r}<0,2$. Tetapi hubungan siklus menstruasi dengan kadar hemoglobin $(\mathrm{r}=$ 0,67), dan kadar hematokrit $(\mathrm{r}=0,86)$ menunjukkan korelasi yang kuat walaupun tidak signifikan $(\mathrm{p}>0,05)$. Korelasi yang signifikan terjadi antara siklus menstruasi dengan jumlah lekosit $(p=0,047)$, dan jumlah eritrosit $(p=0,033)$, karena nilai $p<0,05$.

Adanya tanda negatif menunjukkan makin panjang siklus menstruasi maka makin sedikit jumlah lekosit $(\mathrm{r}=-0,021)$, makin sedikit jumlah trombosit $(\mathrm{r}=-0,014)$. Arah korelasi antara siklus menstruasi dengan jumlah eritrosit, kadar hemoglobin, kadar hematokrit menunjukkan arah positif, artinya makin panjang siklus menstruasi maka tidak menyebabkan jumlah eritrosit, kadar hemoglobin, dan kadar hematokrit tidak berkurang.

\section{Pembahasan}

\section{Analisis Univariat}

Responden dalam penelitian ini adalah siswi kelas VIII SMPN 22 Bandar Lampung, dengan karakteristik sebagai berikut: umur responden rata-rata 13 tahun dengan umur termuda 12 tahun dan umur tertua 14 tahun. 
Responden terbanyak berumur 13 tahun sebanyak 49 siswi $(72,1 \%)$. Rata-rata umur responden pertama kali menstruasi adalah 11 tahun, dan umur responden pertama kali menstruasi termuda 10 tahun dan tertua 13 tahun. Responden pertama kali menstruasi terbanyak berumur 12 tahun sebanyak 26 siswi $(38,2 \%)$.

Siswi SMP merupakan kelompok remaja awal, yaitu masa peralihan antara masa kanakkanak dan masa dewasa yang dimulai kira-kira pada umur 8-14 tahun. Setiap remaja khususnya wanita normal akan mengalami masa pubertas dengan ciri-ciri pertumbuhan yang cepat dan timbulnya ciri-ciri kelompok sekunder, salah satunya adalah menstruasi. Menstruasi didefinisikan sebagai perdarahan secara periodik dan siklik dari uterus, disertai pelepasan (deskuamasi) endometrium. Menstruasi yang berulang setiap bulan tersebut akan membentuk siklus menstruasi (Prawirohardjo, 2005).

Lama menstruasi responden rata-rata 6,6 hari, dengan waktu terpendek 2 hari dan terpanjang 13 hari. Siklus menstruasi responden rata-rata 26,25 hari, dengan waktu terpendek 16 hari dan terpanjang 48 hari. Sebagian besar responden yaitu sebanyak 44 siswi $(64,7 \%)$ mengalami siklus menstruasi normal $(25-32$ hari), sebanyak 22 siswi $(32,4 \%)$ mengalami siklus menstruasi pendek $(<25$ hari), dan 2 siswi $(2,9 \%)$ mengalami siklus menstruasi panjang (> 32 hari). Hasil penelitian ini sama seperti yang dilakukan oleh Wahyuningsih (2012) terhadap mahasiswi Kebidanan di Klaten yang mendapatkan hasil sebagian besar $(71,4 \%)$ mengalami siklus menstruasi yang normal, $19,5 \%$ mengalami siklus menstruasi panjang dan 9,1\% mengalami siklus menstruasi pendek. Hasil penelitian Pratiwi (2016) juga menunjukkan lebih banyak responden yang mengalami pola siklus menstruasi normal (65\%), dibandingkan yang tidak normal (35\%). Hasil penelitian Kirana (2011) pada siswi SMAN 2 Semarang menunjukkan hasil rerata siklus menstruasi adalah 32,6 hari di mana siklus menstruasi terpendek adalah 25 hari dan terpanjang adalah 39 hari. Lama menstruasi 13 hari berkisar antara $3-9$ hari dengan rata - rata 6,2 hari. Sebanyak 38\% responden memiliki siklus menstruasi normal, dan $62 \%$ responden memiliki siklus menstruasi yang panjang. Sebagian besar responden $(97,5 \%)$ memiliki lama hari menstruasi yang normal, dan hanya $2,5 \%$ responden yang memiliki lama hari menstruasi yang tidak normal.
Adanya responden yang mengalami siklus menstruasi yang tidak normal dapat dipengaruhi oleh keadaan psikis dan fisik remaja putri. Menurut Iskandar (2004) wanita yang mengalami gangguan psikis berat seperti stress hebat atau depresi biasanya akan mengalami gangguan hormonal, siklus menstruasi menjadi tidak teratur dan tidak mengalami ovulasi, sehingga dapat mempengaruhi kesuburan. Masa remaja biasanya memiliki siklus menstruasi yang belum teratur, dapat maju atau mundur, hal ini dipengaruhi oleh kondisi fisik dan psikis. Pada masa remaja hormon-hormon seksual belum stabil, namun semakin dewasa biasanya siklus menstruasi semakin teratur. Walaupun ada orang dewasa yang mengalami gangguan menstruasi karena beberapa hal seperti stress dan kelelahan. Menstruasi dapat dipengaruhi oleh faktor genetik, makin teratur siklus menstruasi ibu maka menstruasi anaknya semakin teratur (Iskandar, 2004).

Remaja putri mempunyai resiko terkena anemia, karena mengalami menstruasi setiap bulannya. Semakin lama waktu menstruasi dan semakin panjang siklus menstruasi maka semakin besar kemungkinan terjadinya anemia, karena semakin banyak darah yang keluar dari tubuh. Akibatnya terjadi pengeluaran zat besi yang meningkat dan dapat mengganggu keseimbangan zat besi dalam tubuh, sehingga tubuh kekurangan zat besi. Menurut Manuaba (2009) menstruasi yang tidak teratur dapat dipengaruhi oleh beberapa faktor diantaranya stres, perubahan berat badan, olah raga yang berlebihan dan adanya keluhan menstruasi.

Sebagian besar hasil pemeriksaan profil hematologi dalam batas normal $(61,7-89,7 \%)$, bahkan jumlah lekosit dan jumlah trombosit tidak ada yang rendah (0\%), sedangkan kadar hemoglobin dan kadar hematokrit tidak ada yang tinggi $(0 \%)$. Ada 9 responden $(13,3 \%)$ yang mengalami anemia yaitu mempunyai kadar hemoglobin kurang dari normal $(<12$ $\mathrm{g} / \mathrm{dl}$ ). Responden dalam penelitian ini yang mengalami anemia lebih sedikit jika dibandingkan hasil penelitian Pratiwi (2016) yang mencapai 30,9\% siswi MTs Ciwandan, hasil penelitian Kirana (2011) yang mencapai $36,7 \%$ siswi SMAN 2 Semarang yang mengalami anemia,

Adanya responden yang mengalami anemia ini juga dikuatkan dengan hasil pemeriksaan jumlah eritrosit rendah terdapat pada 3 responden $(4,4 \%)$ dan hasil pemeriksaan kadar hematokrit rendah terdapat pada 13 responden $(19,1 \%)$. Penurunan jumlah eritrosit 
memacu sumsum tulang untuk meningkatkan pelepasan sel-sel eritrosit abnormal yang berukuran kecil dan kekurangan hemoglobin, hal ini berkorelasi dengan kadar hematokrit yang rendah, karena hematokrit merupakan volume eritrosit dalam $100 \mathrm{ml}$ darah.

Menurut Widjanarko (2006), faktorfaktor yang mempengaruhi kadar hemoglobin remaja putri adalah kehilangan darah akibat menstruasi, kurangnya zat besi dalam makanan yang dikonsumsi, penyakit yang kronis, pola hidup remaja putri yang berubah, ketidakseimbangan antara asupan gizi dan aktifitas yang dilakukan. Kurangnya hemoglobin dapat menyebabkan metabolisme tubuh dan sel-sel saraf tidak bekerja secara optimal, menyebabkan pula penurunan percepatan inpuls saraf, mengacaukan system reseptor dopamine (Widjanarko, 2006).

Rata-rata jumlah lekosit responden adalah 8,75 (ribu/ $\mu \mathrm{l})$, dengan jumlah terendah 5,5 (ribu/ $\mu \mathrm{l})$, dan tertinggi 13,7 (ribu/ $\mu \mathrm{l})$. Tidak ada responden yang mengalami kekurangan jumlah lekosit. Dalam penelitian ini didapatkan 11 responden $(16,2 \%)$ mengalami peningkatan jumlah lekosit. Sel lekosit berperan dalam pertahanan tubuh dari serangan benda asing, termasuk adanya infeksi oleh mikroorganisma. Dalam hubungannya dengan menstruasi, peningkatan jumlah lekosit dapat terjadi. Menurut Jones (2005) pada siklus vagina terjadi perubahan siklik di epitelium vagina, yang tergantung pada rasio estrogen dan progesteron. Sel-sel superfisial dan intermediet yang besar mendominasi pada fase folikular. Ketika menjelang ovulasi, proporsi sel superfisial meningkat dan dapat dilihat beberapa leukosit. Setelah ovulasi terjadi perubahan nyata ketika disekresi progesteron. Sel-sel superfisial digantikan sel-sel intermediet, dan jumlah leukosit meningkat (Jones, 2005).

Rata-rata jumlah trombosit responden adalah 352,47 (ribu/ $\mu \mathrm{l})$, dengan jumlah terendah 192 (ribu/ $\mu \mathrm{l})$, dan tertinggi 520 (ribu/ $\mu 1)$. Tidak ada responden yang mengalami kekurangan jumlah trombosit, dan ada 7 responden $(10,3 \%)$ yang mengalami peningkatan jumlah trombosit. Sel trombosit berfungsi dalam pembentukan sumbat (hemostasis). Dalam hubungannya dengan menstruasi, peningkatan jumlah trombosit dapat terjadi. Menurut Jones (2005) Selama menstruasi, lapisan superfisial dan media endometrium dilepaskan, namun lapisan basal profunda dipertahankan. Pengelupasan ini terjadi secara tidak teratur, serampangan, beberapa daerah tidak terganggu, bagian lain mengalami perbaikan, sedangkan tempattempat lain secara serentak dilepaskan. Pembuluh darah yang menyuplai daerah di bawah endometrium yang dilepaskan disumbat dengan sumbat hemostatik yang terbentuk dari agregasi trombosit dan serabut-serabut fibrin yang menginfiltrasi agregat trombosit membentuk plak sumbatan yang stabil. Untuk melakukan sumbat hemostatik ini jumlah trombosit dapat meningkat. Disamping itu juga terjadi vasokonstriksi. Lapisan basal endometrium mengalami regenerasi sehingga epitelium baru menutupi daerah yang terlepas. Apabila regenerasi lebih besar daripada nekrosisnya dan proses perbaikan sudah selesai atau mendekati selesai, menstruasi berhenti dan kemudian siklus menstruasi baru mulai kembali (Jones, 2005).

\section{Analisis Bivariat}

\section{a. Hubungan lama menstruasi dengan jumlah lekosit, trombosit, eritrosit, hemoglobin, dan hematokrit.}

Hubungan lama menstruasi dengan jumlah lekosit, jumlah trombosit, jumlah eritrosit, kadar hemoglobin, dan kadar hematokrit menunjukkan korelasi yang sangat lemah karena nilai $r<0,2$ dan tidak signifikan karena nilai $\mathrm{p}>0,05$ (tabel 5). Adanya tanda negatif menunjukkan makin lama menstruasi maka makin sedikit jumlah lekosit dan makin rendah kadar hemoglobin, sedangkan hubungan antara lama menstruasi dengan jumlah trombosit, jumlah eritrosit, dan kadar hematokrit menunjukkan arah positif, artinya makin lama menstruasi maka makin banyak jumlah trombosit, makin banyak jumlah eritrosit, dan makin banyak kadar hematokrit yang hilang saat menstruasi.

Walaupun hasil penelitian ini menunjukkan korelasi yang lemah dan hubungan yang tidak signifikan antara lama menstruasi dengan profil hematologi (jumlah lekosit, jumlah trombosit, jumlah eritrosit, kadar hemoglobin, dan kadar hematokrit), tetapi dapat dijelaskan bahwa makin lama menstruasi maka makin sedikit jumlah lekosit dan makin rendah kadar hemoglobin, dan makin lama menstruasi maka makin banyak jumlah trombosit, jumlah eritrosit, dan kadar hematokrit yang hilang saat menstruasi. Hal ini seperti dijelaskan oleh Jones (2005) bahwa darah menstruasi mengandung darah vena dan arteri dengan sel-sel darah merah dalam hemolisis atau aglutinasi, sel-sel epitel dan 
stroma yang mengalami disintegrasi dan otolisis, dan sekret dari uterus, serviks, dan kelenjar-kelenjar vulva.

Hasil penelitian ini sejalan dengan penelitian Yamin (2012) yaitu tidak ada hubungan antara lama menstruasi $(p=0,076)$ dengan kadar hemoglobin yang rendah, dan penelitian Kirana (2011) yaitu tidak ada hubungan lama menstruasi dengan kejadian anemia ( $p=0,789$ ) Tetapi tidak sejalan dengan penelitian Pratiwi (2016) yang mendapatkan adanya hubungan antara lama menstruasi dengan kadar hemoglobin yang rendah $(\mathrm{p}=$ $0,000)$

\section{b. Hubungan siklus menstruasi dengan jumlah lekosit, trombosit, eritrosit, hemoglobin, dan hematokrit.}

Hubungan siklus menstruasi dengan jumlah lekosit, jumlah trombosit, dan jumlah eritrosit menunjukkan korelasi yang sangat lemah karena nilai $\mathrm{r}<0,2$. Tetapi hubungan siklus menstruasi dengan kadar hemoglobin dan kadar hematokrit menunjukkan korelasi yang kuat karena nilai $r$ berkisar antara 0,6 - 0,7 walaupun tidak signifikan $(p>0,05)$. Korelasi yang signifikan terjadi antara siklus menstruasi dengan jumlah lekosit dan jumlah eritrosit $(\mathrm{p}<$ $0,05)$. Hasil penelitian ini menunjukkan korelasi yang sangat lemah dan hubungan yang tidak signifikan antara siklus menstruasi dengan profil hematologi (jumlah lekosit, jumlah trombosit, jumlah eritrosit, kadar hemoglobin, dan kadar hematokrit). Responden yang mengalami siklus menstruasi yang panjang ada 2 siswi (2,9\%) yaitu lebih dari 32 hari. Sebagian besar responden mengalami siklus menstruasi yang normal, yaitu sebanyak $64,7 \%$, dan 32,4\% mengalami siklus menstruasi yang pendek.

Hasil penelitian ini sejalan dengan penelitian Yamin (2012) yaitu tidak ada hubungan antara siklus menstruasi $(p=0,513)$ dengan kadar hemoglobin yang rendah, dan penelitian Kirana (2011) yaitu tidak ada hubungan siklus menstruasi dengan kejadian anemia ( $p=0,789)$

Lama menstruasi dan siklus menstruasi yang tidak normal merupakan suatu gangguan menstruasi. Gangguan menstruasi paling umum terjadi pada awal dan akhir masa reproduktif, yaitu di bawah usia 19 tahun dan di atas usia 39 tahun. Gangguan ini mungkin berkaitan dengan lamanya siklus menstruasi, atau jumlah dan lamanya menstruasi. Seorang wanita dapat mengalami kedua gangguan itu. Gangguan pada lamanya siklus menstruasi ada yang disebut polimenore atau epinore. Pada polimenore siklus menstruasi lebih pendek dari biasanya yaitu terjadi dengan interval kurang dari 21 hari. Perdarahan kurang lebih sama atau lebih banyak dari biasa. Polimenore dapat disebabkan oleh gangguan hormonal yang mengakibatkan gangguan ovulasi, atau menjadi pendeknya masa luteal. Sebab lain adalah kongesti ovarium karena peradangan, endometriosis, dan sebagainya (Jones, 2005).

Selain polimenore, ada gangguan oligomenore yaitu siklus menstruasi lebih panjang dari normal yaitu lebih dari 35 hari. Perdarahan pada oligomenore biasanya berkurang. Pada kebanyakan kasus oligomenore kesehatan wanita tidak terganggu, dan fertilitas cukup baik. Siklus menstruasi biasanya ovulatoar dengan masa proliferasi lebih panjang dari biasanya. Serta gangguan amenore yaitu keadaan tidak adanya menstruasi sedikitnya tiga bulan berturut-turut. Amenore primer terjadi apabila seorang wanita berumur 18 tahun ke atas tidak pernah mendapatkan menstruasi, sedangkan pada amenore sekunder penderita pernah mendapatkan menstruasi tetapi kemudian tidak dapat lagi (Jones, 2005).

Gangguan jumlah darah menstruasi dan lamanya perdarahan dikelompokkan menjadi dua yaitu hipomenore dan hipermenore atau menoragia. Hipomenore yaitu perdarahan menstruasi yang lebih pendek dan atau kurang dari biasa dengan discharge menstruasi sedikit atau ringan. Penyebabnya adalah kurang suburnya endometrium karena kurang gizi, penyakit menahun maupun gangguan hormonal. Hipermenore adalah perdarahan menstruasi yang lebih banyak dari normal (lebih dari 8 hari). Penyebabnya adalah adanya myeioma uteri, polip endometrium, gangguan pelepasan endometrium dan sebagainya (Jones, 2005).

Simpulan penelitian ini yaitu hubungan lama menstruasi dengan jumlah lekosit, jumlah trombosit, jumlah eritrosit, kadar hemoglobin, kadar hematokrit menunjukkan korelasi yang sangat lemah dan tidak signifikan $(p>0,05)$, yaitu makin lama menstruasi maka makin sedikit jumlah lekosit, dan makin rendah kadar hemoglobin, tetapi makin banyak jumlah trombosit, jumlah eritrosit, dan kadar hematokrit.

Hubungan siklus menstruasi dengan jumlah lekosit, jumlah trombosit, dan jumlah eritrosit menunjukkan korelasi yang sangat lemah. Tetapi hubungan siklus menstruasi dengan kadar hemoglobin dan kadar hematokrit menunjukkan korelasi yang kuat walaupun 
tidak signifikan $(\mathrm{p}>0,05)$. Korelasi yang signifikan terjadi antara siklus menstruasi dengan jumlah lekosit dan jumlah eritrosit, karena nilai $\mathrm{p}<0,05$. Hubungan ini menunjukkan makin panjang siklus menstruasi maka makin sedikit jumlah lekosit, makin sedikit jumlah trombosit. Tetapi hal ini tidak menyebabkan jumlah eritrosit, kadar hemoglobin, dan kadar hematokrit tidak berkurang.

Saran yang dapat diberikan untuk responden yang mengalami anemia sebanyak $13,3 \%$, agar mendapatkan fortifikasi zat besi sesuai dengan dosis yang dibutuhkan. Untuk menjaga agar remaja putri tidak mengalami anemia karena siklus menstruasinya, maka harus menjaga asupan dengan gizi seimbang dan tidak memilih makanan yang hanya sesuai selera nya saja.

\section{Daftar Pustaka}

Bobak, M; Irene et, al. (2004). Keperawatan Maternitas. edisi 4, Jakarta: EGC.

Handayani , Andi Sulistyo Haribowo. 2008. Asuhan keperawatan pada klien dengan gangguan sistem hematologi. Salemba Medika : Jakarta

Jones, D.L., 2005. Haid. Dalam: Setiap Wanita. Jakarta: Delapratasa Publishing Kirana, D P; Apoina Kartini. 2011. Hubungan Asupan Zat Gizi Dan Pola Menstruasi Dengan Kejadian Anemia Pada Remaja Putri Di SMAN 2 Semarang. Skripsi. Prodi Ilmu Gizi Fakultas Kedokteran. Universitas Diponegoro. Semarang

Manuaba, IBG.2009. Kapita Selekta Penatalaksaan Rutin Obstetri Ginekologi dan Keluarga Berencana. Jakarta : EGC

Pratiwi, E. 2016. Faktor-faktor yang mempengaruhi anemia pada siswi MTS Ciwandan Cilegon-Banten tahun 2015. Skripsi. UIN Syarif Hidayatullah. Jakarta.

Proverawati, 2011. Anemia dan anemia Kehamilan. Nuha Medika. Yogyakarta.

Permaesih, D; Susilowati, H. Faktor-Faktor Yang Mempengaruhi Anemia Pada Remaja. Bulletin Penelitian Kesehatan, 2002. Vol. 33 No. 4. 2005:162-171

Pulungan,2010. Pubertas dan Gangguannya Buku Ajar Endokrinologi Anak. Edisi pertama. UKK Endokrinologi Anak dan Remaja IDAI : Jakarta.

Sandra, F., Ahmad Syafiq, Sri Nurjuaida. 2005. Pengaruh Suplementasi Zat Besi Satu
Dan Dua Kali Per Minggu Terhadap Kadar Hemoglobin Pada Siswi Yang Menderita Anemia. Universa Medicina 24 (4) 2005

Survei Kesehatan Rumah Tangga (SKRT) Pedoman Penanggulangan Anemia Gizi Untuk Siswi SMPN Dan Wanita Usia Subur. Jakarta : Depkes ; 2004.

Wahyu, P H, Riri Novayelinda, Jumaini. 2015.Hubungan Status Gizi dengan Kejadian Anemia Pada Remaja Putri. Jom 2 (1) 2015

Wahyuningsih, A., Sari Puji Astuti. (2012). Hubungan Kadar Hemoglobin dengan Keteraturan Siklus Menstruasi Pada Mahasiswi Prodi D III Kebidanan Tingkat III Stikes Muhammadiyah Klaten. Jurnal Involusi Kebidanan 2 (3) 2012

Widjanarko, B. 2006. Tinjauan terapi pada nyeri haid primer (Vol.5). Jakarta: Majalah Kedokteran Damianus.

WHO. (2008). Iron Deficiency Anemia assessment, Prevention and Control. A guide for Programe Manager. 2008

Yamin, Tenri. 2012. Hubungan pengetahuan, asupa gizi dan faktor lain yang berhubungan dengan kejadian anemia pada remaja putri di SMA Kabupaten Kepulauan Selayar. Skripsi. Fakultas Kesehatan Masyarakat Uiversitas Indonesia. Depok 